\title{
Études littéraires africaines
}

\section{Nouvelle formule des ELA}

\section{Daniel Delas}

Numéro 13, 2002

URI : https://id.erudit.org/iderudit/1041794ar

DOI : https://doi.org/10.7202/1041794ar

Aller au sommaire du numéro

Éditeur(s)

Association pour l'Étude des Littératures africaines (APELA)

\section{ISSN}

0769-4563 (imprimé)

2270-0374 (numérique)

Découvrir la revue

\section{Citer ce document}

Delas, D. (2002). Nouvelle formule des ELA. Études littéraires africaines, (13), 1-1. https://doi.org/10.7202/1041794ar

Tous droits réservés (c) Association pour l'Étude des Littératures africaines (APELA), 2002
Ce document est protégé par la loi sur le droit d'auteur. L'utilisation des services d'Érudit (y compris la reproduction) est assujettie à sa politique d'utilisation que vous pouvez consulter en ligne.

https://apropos.erudit.org/fr/usagers/politique-dutilisation/ 


\section{Nouvelle formule des ELA}

$A^{\text {vecos }}$ vec ce numéro 13 qui, nous l'espérons, nous portera chance, commence la nouvelle formule de notre revue bisannuelle, Etudes littéraires Africaines. L'Assemblée Générale du Congrès de Montpellier avait, vous vous en souvenez, approuvé l'idée, associée à la mise en place du site www.apelaasso.net d'un partage du contenu de chaque numéro entre des compte rendus et un dossier thématique. Comme cela réduisait évidemment la place disponible pour les comptes rendus, l'équipe rédactionnelle (D. Delas, $P$. Halen et A. Ricard) a utilisé au mieux nos deux supports, en reportant en ligne les comptes rendus "littéraires".

Que signifie cet adjectif entre ces guillemets chers aux universitaires ? Que nous privilégions les comptes rendus de réflexion scientifique pour la publication papier, mais sommes très soucieux d'accueillir des réactions critiques sur des cuvres de fiction ou de la poésie, quelle qu'en soit la visibilité universitaire. $N^{\prime} h e ́ s i t e z$ pas à nous adresser des textes personnels, notre site va s'organiser progressivement et leur faire une place.

Faites-nous part de vos réactions à la nouvelle formule, par courrier (papier ou électronique) ou lors des assemblées générales qui se veulent des forums de discussion, avec des suggestions, des propositions, voire des critiques.

La réflexion sur les littératures africaines et les poétiques, positives ou négatives, dont elle sont porteuses est essentielle pour elles-mêmes mais aussi pour les sociétés occidentales et africaines. Il importe de la maintenir vivante par du travail concret d'analyse et de synthèse.

C'est ce qu'on essaye de poursuivre aujourd'hui, dans l'esprit originel de l'Apela, indépendant et pluriel.

- Daniel Delas

Rédacteur en chef (danieldelas@aol.com) 